\title{
FUNCIONARIOS PROVINCIALES
}

Su clasificacion. - ¿Naturaleza estatal o provincial?Funcionarios de la Administración Central encargados de la fiscalización de la Provincial.-Funcionarios administrativos; Secretarios e Interventores; otros funcionarios.-Funcionarios técnicos.-Reclutamiento de los funcionarios. - El Gerente director de los servicios.

Corresponde examinar, en primer término, lo relativo a los funcionarios provinciales, administrativos y técnicos. Es este problema que tiene muy señalada importancia en la organización de la Administración provincial, como tiene siempre el problema de los funcionarios de la Administración general en cualquiera de sus esferas. La buena marcha de la administración, naturalmente, tiene que depender de la buena preparación, de la buena gestión realizada por aquellas personas físicas que, como titulares de una función pública, se convierten en órganos de la Administración.

La materia de funcionarios provinciales da lugar a una serie de problemas de mucha significación y de índole bien distinta. Los funcionarios provinciales, ison todos de la misma naturaleza? ¿ Hay variedad de naturaleza en las funciones de ellos? Además de la división corriente en la administración, de funcionarios de escala técnica y funcionarios de escala auxiliar, i hay otras distinciones que hacer? Al hablar de funcionarios de la Administración provincial, ¿todos los que actúan en esa esfera son propiamente funcionarios provinciales o, por el contrario, deben algunos ser considerados como funcionarios del Estado?

Se clasifican los empleados o funcionarios provinciales en generales, los encargados de los servicios generales de la Administración provincial, Secretaría, Contaduría y Depositaría, según el texto de

50 (*) Del libro recientemente publicado por el Instituto de Estudins de Administración Local, sAdministración Provincial Española. Sus prcblemass. 
la Ley de 1882, y los funcionarios encargados de servicios especiales. En éstos, en los encargados de servicios especiales, surge inmediatamente la diferencia entre los funcionarios técnicos, prupiamente técnicos del servicio especial de que se trata, y funcionarios administrativos, adscritos para la parte administrativa de la realización de ese fin técnico especial.

Si nos fijamos, no en la legislación española de momento, sino en otra legislación extranjera, para ver cómo se plantea este problema, advertimos que en los funcionarios de la Administración local, por ejemplo, en Italia, se distinguen los funcionarios honoríficos, de nombramiento actualmente autoritario, por el Gobierno, el Podestà, los miembros de la Consulta, los funcionarios administrativos retribuídos, de nombramiento, salvo excepción en algún caso, del mismo ente de que se trata. Diferenciación entre empleados, los asimilados al concepto técnico legal de funcionarios, y los asalariados o agentes de la administración, distribuídos unos y otros en servicios de carácter general y servicios especiales, por ejemplo, servicios de policía, cuando este servicio corresponde, no sólo al Estado, sino también a entidades locales, como acaece con la existencia de policía municipal en Francia, Italia, etc., servicio de higiene, servicio de beneficencia, servicio de obras públicas, servcio financiero, servicio de estado civil, y tantos otros que pudieran mencionarse.

Pero, cosa curiosa, ya que me refiero a la legislación italiana: el cargo más importante en la administración municipal, desde el punto de vista funcionarista, es el del Secretario, y. el Secretario no es funcionario municipal, es funcionario del Estado. La legislación italiana los clasifica en ocho categorías: las cuatro primeras figuran con una escala única nacional, el nombramiento corresponde al Ministro del Interior; las cuatro segundas categorías son de naturaleza provincial y corresponde al Prefecto su nombramiento. Se exige para algún caso especial, como el de Oficial sanitario, nombramiento también del Gobierno. ¿Habrá, pues, que examinar, cuando se trata de este género de funcionarios, si todos los que actúan en la Administración provincial deben ser funcionarios provinciales, netamente funcionarios locales o, por el contrario, podrá haber alguno que tenga la consideración de funcionario del Estado? En Italia, en general, se aplica lo que acabo de decir para la Administración municipal a la Administración provincial, y la tendencia actual es el equiparar lo provincial al régimen municipal. El Secretario en la provincia es todavía un funcionario local, un funcionario del ente provincial, pero 51 
la tendencia es a transformarlo en funcionario del Estado. ¿Por qué se advierte esta singularidad?

Nosotros hemos venido considerando los funcionarios provinciales y municipales como funcionarios netamente locales; su designación correspondía, según la Ley del 77, municipal, y la del 82, provincial, a las respectivas Corporaciones. El Estado, en razón a dar garantía jurídica al funcionario, fué cuidando a través del tiempo, al mismo ritmo un poco atrasado de ir dando un Estatuto al funcionario estatal, de ir dando Reglamentos, bien interiores-Reglamentos debidos a las propias Corporaciones-, bien después a normas de carácter general, que señalasen las normas del Reglamento que cada Corporación pudiera redactar para los funcionarios de entidades locales; pero a medida que se va estableciendo un más íntimo enlace entre la gestión de asuntos de entidades locales y delegados del Poder central, negando la idea de autonomía, admitiendo sólo la existencia de una esfera autárquica, un señalamiento de materias en que actúa el órgano localizado, a medida que se considera que hay que acentuar con el mantenimiento de la unidad políticoadministrativa la intervención del Poder central en los asuntos locales, surge preguntar, si existiendo funcionario, como el Alcalde, nombrado por el Gobierno, ¿ por qué no haber un Secretario de la Corporación y un Jefe de los funcionarios de la Administración municipal, nombrado también por el Gobierno? Si el Gobernador interviene y tiene potestad para suspender determinados acuerdos que adoptan las Corporaciones provinciales, si el nombramiento de Jefe provincial de la Administración provincial se hace por el Gobierno central, ¿ por qué no hacer los nombramientos y dar consideración de funcionarios centrales a los Jefes de las oficinas provinciales? ¿Es que no habría posibilidad de realizar una inspección, una más adecuada fiscalización de los actos de las autoridades provinciales y municipales, teniendo algunos de los funcionarios que dirigen esa administración, en relación directa con la Administración central y teniendo el carácter, no de funcionarios locales, sino de funcionarios estatales? En España, ¿cuál es la situación legal, qué orientación existe en esta materia?

En España, los funcionarios de Administración provincial tienen el carácter de funcionarios provinciales. Existe mantenido el capítulo respectivo del Estatuto provincial de 1925; en virtud de los Decretos de revisión del año 1931, no hay modificación legal en el nuevo régimen en esta materia, hasta las nuevas normas que como con52 secuencia de la creación del Instituto de Estudios de Administración 
local y la creación en el mismo de la Escuela Nacional de Funcionarios de Administración local. La Ley de 6 de septiembre de 1940 y su Reglamento de 24 de junio de 1941 crean una institución nueva como institución del Estado, puesto que, salvo la Escuela de funcionarios de Administración local que existió en Barcelona, habían existido varios proyectos de creación de Escuelas de funcionarios locales, pero no se habían llevado a la realidad hasta ahora; la Escuela tiene carácter nacional, sin perjuicio de la descentralización de sus servicios, de que haya centros locales para la preparación de ciertas categorías de funcionarios.

Cuando se publicó en el año 40 la Ley del 23 de noviembre sobre provisión de plazas vacantes en la Administración local, se decretó la apertura de concursos para el nombramiento de Secretarios, de Interventores y de Depositarios; pero el concurso se hizo por la Dirección general de Administración local. Se resolvió por ella, previa audiencia de la Corporación y a propuesta en terna de un Tribunal calificador, que en los servicios centrales se componía de un Magistrado, de un Abogado del Estado y de un Jefe de Sección del Ministerio. Cuando se trata de Secretarios municipales de tercera categoría, son los Gobernadores los que actúan, y contra los fallos dictados en la resolución del concurso cabe la alzada al Ministro de la Gobernación. Es decir, que hay un enlace entre la Administración local y la Administración general del Estado, que la designación no se hace por obra exclusiva de la Administración local, sino que hay una intervención de órganos centrales; pero no basta indicar esto. Me lleva la existencia de este enlace entre la legislación española y lo que he indicado acerca de la legislación italiana al planteamiento de otro problema fundamental en este punto de enlace entre la Administración general del Estado y las Administraciones locales, y es el de los servicios que la Administración general tiene que tener en el centro, en esta denominada Dirección General de Administración local, relativos a la vida de las Corporaciones tanto provinciales como municipales y la clase de funcionarios que deban actuar en los. mismos.

Hablar de funcionarios de la Administración provincial y no referirnos al enlace entre esta Administración y los servicios de la Administración central sería dejar el cuadro incompleto. Porque, sea cual sea el criterio en materia de designación de funcionarios de $\mathrm{Ad}$ ministración provincial, ya que concretamente examino esta esfera, siempre surgirá esta pregunta : ¿cómo resultarán mejor atendidos los servicios de inspección, cómo resultarán mejor atendidos los servi- 53 
cios de fiscalización a realizar por la Administración central? La inspección, la intervención central era cumplimiento de un precepto de carácter constitucional, con arreglo a las normas del artículo 84 de la Constitución de 1876; en todo momento, en razón de la facultad que se atribuye al Gobernador civil respecto de las decisiones adoptadas por la Corporación para poderlas suspender. de las reclamaciones que se entablen contra actos de los Gobernadores, de los recursos que pueden interponer los particulares, de múltiples incidencias de la Administración provincial que atañen a la esfera central, se plantea el problema de qué funcionarios son los que deben tener a su cargo todo lo que en la Administración central se refiere a la propia Administración provincial y municipal. Si advertimos, creo yo que acertadamente, cómo se ha tratado de ir dando cada día más carácter técnico, de más especialidad en la Administración central, a determinados servicios de ella, acentuando ese carácter técnico, como, por ejemplo, con la creación de la secretaría Técnica de la Dirección General de Administración local, habrá que preguntarse qué funcionarios son los que deban desempeñar tal puesto, quiénes los que deben dar el asesoramiento técnico a los órganos activos de la Administración central, órganos que, naturalmente, son de carácter más bien político que técnico, como lo son el cargo de Subsecretario, de Director general de Administración local, dado su nombramiento político, no netamente administrativo. La respuesta que se impone es la de que cuanto más se acentúe en quien decide el carácter político del cargo, más hay que acentuar en quien prepara y auxilia al elemento político el carácter técnico, y, por consiguiente, aunque se trate de servicios que radiquen en el centro, el reclutamiento de esos funcionarios hay que buscarle entre los que hayan cultivado la especialidad, entre los conocedores de los servicios locales que motivan actividad en oficinas centrales.

¿Quién podrá inspeccionar mejor unas servicios de índole municipal o provincial: quien no haya prestado servicios en esa esfera o quien en determinada categoría elevada de ella, durante un cierto período de años, haya prestado esos servicios? Evidentemente, la técnica y la práctica facilitarían la mayor eficacia de la acción del órgano central respecto de la Administración local. La conveniencia del interés del servicio lleva para mí a la conclusión de que hay que reclutar para la Administración central determinados funcionarios entre los escalafones de carácter técnico que el mismo Estado ha creado en las leyes orgánicas provincial y municipal para la Cor54 poración respectiva. 
Lleva esto al planteamiento de otro problema, el problema del Estatuto singular de esos funcionarios locales actuantes en el Centro, la necesidad de resolverlo, no estableciendo oposición entre las categorías e índole de sus servicios, no creando solución de continuidad entre su situación como funcionarios netamente locales y la situación como funcionarios de la Administración central, sino estableciendo el debido enlace en razón a sus servicios, ya que siendo todos ellos de carácter oficial, y no pudiendo considerarse compartimentos estancos en absoluto las entidades de carácter local y el Estado de que forman parte, hay medios no difíciles de hallar para solucionar lo que afecta a la situación individualizada de esos funcionarios, en consideración a la índole de los servicios que prestan y a la esfera en que los vienen prestando. Dejo este punto no más que como indicación, porque el tiempo no permite un mayor desenvolvimiento.

Fijándonos en los empleados, ya concretamente, de Administración provincial, hay que partir de la distinción corriente de funcionarios técnicos y funcionarios llamados administrativos por unos, burocráticos por otros. Técnico denominan algunos, no al que presta servicio especial, sino a aquéllos que para adquirir la condición de empleados han necesitado la posesión de un título académico; burocráticos, los de índole netamente administrativa, que han necesitado, para tener la condición de empleado, un título oficial de índole administrativa; actualmente diríamos el diploma de la Escuela Nacional de Funcionarios. Funcionarios especiales, en algún proyecto de los redactados, se han considerado a todos aquéllos de profesión especial, no académica; funcionarios subalternos, a aquéllos que desempeñan funciones manuales secundarias o puramente mecánicas, quedando todavía otras categorías, como las de los guardias y agentes armados, que requieren para su función el uso de armas, categoría mucho más importante en la Administración municipal, numéricamente, que en la Administración provincial.

Los funcionarios de la Administración provincial divídense por la Ley de 1882 y Estatuto de 1925, en funcionarios técnicos o especiales. Esta diferenciación existía ya en la Ley de 1882, no tan acentuada como lo está en el Estatuto provincial. La Ley de 1882 hablaba de la Secretaría, de la Contaduría y de la Depositaría. El artículo 104 atribuye a la Corporación el nombramiento y separación de los funcionarios, pero hacía referencia al número $4 .^{\circ}$ del artículo 74 de la misma Ley para los funcionarios de orden profesional, para los técnicos especiales, llamando la atención sobre los Reglamentos y 55 
condiciones singulares exigidas por el Reglamento de régimen interior aprobado por las mismas Corporaciones. El artículo 142 establece los deberes en relación a la jerarquía. y no había un gran desarrollo de la materia "empleados de Administración provincial" en la Ley, siendo reducido el número de artículos que se dedicaban a ello, justificándose los intentos de reforma de la Ley provincial no sólo en este punto, sino en otros, y cómo se llega al Estatuto de 1925 y a una modificación importante en la materia que examino. El Estatuto, que constituye Derecho vigente, indica que en cada Diputación o Cabildo insular habrá un Secretario pagado con fondos provinciales o insulares, que será el Secretario del Pleno y de la Comisión provincial, en su caso, o Cabildo.

Se diferencia con relación a la Secretaría dos órdenes de funciones: las que le corresponden formando parte de la Corporación provincial y las como Jefe de los Servicios administrativos de la Diputación.

Como miembro de la Corporación (artículo 136), asiste sin veto a las sesiones del Pleno, hoy de la Comisión gestora, antes se agregaba "y de la Comisión provincial", dando cuenta de la correspondencia y de los asuntos comprendidos en la convocatoria $u$ orden del día; levanta las actas, advierte a la Diputación y al Presidente, en su caso, de la ilegabilidad, si la hubiere, de cualquier acuerdo que pretendiese adoptar, consignando en acta su protesta en su caso, a fin de eximirse de la responsabilidad que pudiera caberle; asiste a todos los actos oficiales de la Diputación y Comisión, vigila la ejecución de acuerdos, gestiona todos los asuntos de la Corporación. siempre que así lo disponga el Presidente, y cuida de la redacción y publicación semestral de los extractos de acuerdos administrativos de la Corporación (artículo 137).

Como jefe de los servicios, debe permanecer en su despacho las horas señaladas para oficina, debe dirigir y vigilar los empleados de la Secretaría, preparar los expedientes que ha de resolver la Corporación, cuidar de que se expidan gratuitamente, sin perjuicio de los reintegros exigidos por la Ley del Timbre, recibos de reclamaciones, solicitudes y recursos; certificar de todos los actos y documentos oficiales de la Corporación, redactar las memorias anuales dando cuenta de los servicios de la Diputación, custodiar y ordenar el archivo cuando no hubiere funcionario técnico especial.

Para ser Secretario se exige ser español, varón, de estado seglar, mayor de veinticinco años, hallarse en el pleno goce de sus derechos civiles y políticos, tener el título de Licenciado en Derecho y haber 
acreditado la aptitud legal en la forma reglamentaria. Al Reglamento dejó el Estatuto fijar las demás condiciones precisas para el ingreso, previa oposición, en el Cuerpo correspondiente; el régimen de ascensos, la declaración y provisión de vacantes y la regulación de derechos pasivos, etc. El Reglamento procurará fusionar los Cuerpos de Secretarios de Diputaciones provinciales y de Ayuntamientos, establecerá reciprocidad entre los aspirantes, armonizando la autonomía de las Corporaciones provinciales.

Al lado de los Secretarios, el Estatuto preveía la existencia de un Interventor de fondos (artículo 148), encargado de la cuenta y razón y de fiscalizar todo ingreso o gasto hecho por la Corporación. Señala el artículo 149 como sus funciones: llevar los libros de contabilidad. dirigir la oficina de cuenta y razón, extender los cargaremes y libramientos de todos los pagos, preparar y conservar los presupuestos ordinario y extraordinario, formar las cuentas de presupuestos y propiedades, los balances trimestrales y liquidaciones generales de cada presupuesto, autorizar las nóminas de empleados, informar los expedientes de fianzas y de reintegro, conservar una de las tres llaves de la caja de caudales, asistir a los arqueos, pasar diariamente nota de la situación de fondos, cumplir los deberes que el Reglamento de empleados municipales de 1924 impone en lo pertinente al caso y redactar una memoria expresiva del estado económico de la Corporación. El Interventor debe negarse (artículo 150) a todo pago de gastos que no tenga consignación en presupuestos, oponerse a que los fondos o valores estén en poder de particulares y no en las arcas provinciales; debe dar cuenta del retraso en los ingresos, formular oposición ante la Corporación, a que en los pagos sean infringidas las prioridades que se deriven de títulos legítimos. Fl Interventor tiene voz en las sesiones para cumplir las obligaciones que le impone este artículo. Para ser Interventor hace falta también pertenecer al Cuerpo oficial de Interventores de la Administración local.

Al lado del Secretario y del Interventor hay funcionarios administrativos burocráticos de la Corporación, e independientemente de ellos, de los administrativos y de los auxiliares, están en el grupo de los que llama el Estatuto "demás empleados de la Administración provincial", los Ingenieros, Arquitectos, Abogados, Médicos, Farmacéuticos, Veterinarios, Archiveros, Practicantes y demás funcionarios técnicos titulados de la Diputación, que ingresarán, según la respectiva Corporación acuerde, por oposición o por concurso. Respetando la autonomía de las Corporaciones, el Gobierno podrá dictar 57 
Reglamentos de carácter general para impedir que la Diputación desatienda sus servicios técnicos o los encomiende a personal falto de garantía titulada oficial.

La Diputación está obligada, según el artículo 154, a formar Reglamentos que determinen las condiciones de ingreso, ascensos, sueldos, licencias, sanciones, separación, derechos pasivos, funciones y deberes de los funcionarios provinciales, Reglamentos que deben ser distintos en cuanto a sus deberes y derechos para el personal técnico y administrativo y el subalterno, ajustados a las garantías logales.

Adviértese, pues, que el criterio legal es: unos funcionarios jefes de los servicios netamente administrativos y de los económicos, funcionarios técnicos especiales y empleados administrativos.

¿Cómo organizar estos Cuerpos de funcionarios? ¿Qué sistema es el que debe aceptarse para la designación de ellos? Son distintos los servicios que han de prestar las categorías diferentes de funcionarios que he mencionado. No cabe someter al mismo criterio lo referente a la formación de un Cuerpo de Secretarios un Cuerpo de Interventores o de Médicos de la Beneficencia provincial o de Ingenieros o Arquitectos provinciales. ¿Ha de ser el nombramiento libre?, ¿por concurso de méritos?, ¿mediante ejercicios de oposición?

El nombramiento libre no es el mejor sistema. Es conveniente exigir la demostración de la aptitud para el desempeño del cargo. ¿Cómo mostrar que se tiene esa aptitud? El sistema del concurso de méritos pudiera utilizarse, pero la experiencia muestra que no basta seguir tal sistema para la mejor selección, no sólo por la dificultad en señalar clara y debidamente cuáles deben ser los méritos a tener en cuenta y su respectiva preferencia, sino por las dificultades de examinar comparativamente por modo interno, en lo esencial, los méritos de igual epígrafe, aparentemente de la misma naturaleza, de unos y otros aspirantes. El sistema de oposición se ha preferido y e! Estatuto provincial lo admite como el más adecuado.

La oposición, evidentemente, puede mostrar la aptitud, la capacidad para el desempeño del cargo, pero no siempre puede decirse que ese sistema sea realmente el mejor. Algunos le han calificado como el menos malo de los diversos sistemas, y por eso no puede extrañar que, siguiendo el ejemplo de otras profesiones, se pensara en la creación de Escuelas especiales de preparación para estos órdenes de funcionarios.

Inmediatamente surge la necesidad de establecer distinción entre las distintas clases de funcionarios. La preparación no puede ser igual 
para un Secretario que para un Interventor, aunque hay estudios que son comunes para ambos; la preparación tiene que ser distinta para un funcionario administrativo letrado que para un Ingeniero, un Arquitecto o un Médico de la Administración provincial.

La organización de los Cuerpos admiristrativos puede hacerse. y es el sistema que dará los mejores resultados, mediante la existencia de la Escuela especial. En primer lugar porque, exigiéndoles un título académico-en este caso para ser Secretario-que supone una primera selección; estableciendo un cierto orden de estudios, no todos teóricos, sino tcórico-prácticos, durante determinado período de tiempo, los aspirantes que han sido seleccionados entre los que poseen un mismo título académico irán demostrando en el curso de sus trabajos sus aptitudes, aptitudes de distinta naturaleza a contrastar, porque, además de los conocimientos especiales, de la instrucción, se requiere conocimiento de la persona. de sus condiciones de asiduidad, competencia, de iniciativa, de decisión, que se irán mostrando en cada uno de los trabajos en el Centro, conocimiento muy superior al que pueda lograrse en unos ejercicios de oposición, en los que en ocasiones el azar, la suerte y el estado físico en que el oriositor se encuentre en determinado momento, pueden influir.

La tendencia favorable a este sistema permite esperar que al iniciarse ahora en España el sistema de provisión de cargos de esta naturaleza mediante el pase por la Escuela nacional de funcionarios de Administración local venga a robustecer más las ventajas que ya se habían adquirido mediante el sistema de la oposición.

Es un hecho cierto que se nota una mejor preparación técnica en estos grupos de funcionarios desde que se modificó el reclutamiento de los mismos, desde que el sistema de la oposición y la exigencia del título académico han sido elementos básicos para su reclutamiento.

Es también un hecho cierto que mediante la especialización, mediante la efectuación de una serie de trabajos prácticos y de un conocimiento previo de los mismos servicios podrá llegarse al desempeño de los cargos con una preparación mucho más adecuada que anteriormente.

$\mathrm{Si}$, además, como algunos desean, como se hace en determinadas legislaciones extranjeras, se exigiera no sólo el pase por la Escuela, sino durante un cierto período de tiempo la práctica material de los servicios en la propia esfera de la Administración en que después hubieran de prestarse; si al salir de. la Escuela sólo se obtuviera nombramiento provisional a confirmar en mérito de los informes sobre 
las condiciones en que el servicio hubiere sido prestado en el período de prueba, todavía se obtendría más ventaja. Y si en ocasiones, cuando existe diversidad de naturaleza de funciones según el grado jerárquico en el propio Cuerpo administrativo, se estableciera exigir alguna nueva prueba, algún nuevo concurso para cambiar de categoría, evitando que pueda haber un estancamiento del funcionario, obligando así a que éstos sintieran la absoluta necesidad de estar constantemente perfeccionando su su preparación, evidentemente que el camino de progreso hace tiempo ya iniciado en la Administración española habría de intensificarse para llegar en un porvenir no muy lejano a lo que se estima como ideal en la recluta y formación de los funcionarios.

Pero estos funcionarios de carácter administrativo no son los únicos que interesan a la Administración provincial. La índole de los servicios específicos de la Administración provincial, como veremos luego, requiere funcionarios técnicos: arquitectos, mẻdicos, farmacéuticos, veterinarios, ingenieros en sus diversas modalidades-de Montes, de Caminos, Agrícolas, etc., etc.- Todo ello supone el planteamiento del mismo problema del reclutamiento de estos funcionarios, algunos de los cuales han pasado por su Escuela técnica, por ejemplo, los ingenieros y los arquitectos; otros han pasado por una Escuela o Centro de enseñanza superior, pero no han adquirido sino un título más bien científico que propiamente de orden profesional; sobre todo, no han adquirido, en algunos casos, el diploma o título de la especialización del servicio concreto que han de desempeñar.

No cabe hablar aquí de la existencia de una Escuela especial para cada uno de estos órdenes de funcionarios, pero sí cabría hablar de la existencia de algunas enseñanzas especiales complementarias, en unos casos, de la Escuela especial general. Por ejemplo: Ingeniería y Arquitectura con aplicación a los servicios provinciales, y en materia de Medicina, por la especialización del servicio que hubiere de tener. En una palabra, buscar la especialización técnica en relación con el servicio que haya de ejercitarse.

La variedad técnica obliga a no fundir en un solo Cuerpo a estos funcionarios, únicos en algún caso, varios en otros, regulando separadamente por servicios su particular situación.

¿Han de constituir un solo Cuerpo los funcionarios técnico-administrativos de la Administración local o, por el contrario, conviene establecer separación entre los funcionarios netamente municipales 60 y los provinciales? 
Razones hay en pro de una y otra solución. Cuando las Diputaciones aparecían como superiores jerárquicos de los Ayuntamientos parecía que fundir en un solo Cuerpo a los funcionarios, perteneciendo unos a los juzgadores y otros a los juzgados, podía tener sus inconvenientes. Cuando desapareció de las Corporaciones provinciales este carácter de superior jerárquico de los Ayuntamientos el inconveniente desapareció.

Funciones de naturaleza idéntica-Interventores y Secretariosadmiten la posibilidad de un solo Cuerpo. La preparación puede ser común en todo lo fundamental; el servicio es de la misma naturaleza; no hày razón de fondo para argumentar en contra de la existencia de un Cuerpo de Secretarios y de otro de Interventores.

Ahora bien: ¿es que hemos agotado la enumeración de empleados, de funcionarios-para decirlo en término más genérico-de la Administración local?

Creo que no, y creo que conviene suscitar algo de lo que se ha hablado cuando se ha tratado de la Administración municipal, pero de lo que no se ha tratado con referencia a la Administración provincial. Me refiero a la institución Gerente, del Gestor Jefe administrativo provincial.

Adviértase que ahora se llama el órgano colegiado provincial "Comisión Gestora", y que desde hace años, en lugar de hablar de las Corporaciones, de los Ayuntamientos o Diputaciones provinciales, se habla de las Gestoras.

Las Corporaciones, incluso en los Municipios, durante un cierto período de tiempo-en época de la República—se sustituyeron legalmente por las Comisión gestoras; y en las provincias, a la Diputación y a la Comisión provincial sustituyó la Comisión gestora.

Se trata de gestores de servicio; se trata de la conveniencia de pensar que en estas esferas de administración hay dos órdenes distintos de funciones: una, funciones de autoridad, de gobierno, y otra, de mera actuación; función de carácter exclusivamente de administración en el sentido corriente de esta palabra, funciones de carácter económico, funciones de gestión de servicios de índole económica, de índole industrial, porque, aun en aquellos servicios que tienen otra consideración-la social-, como el de Beneficencia, el funcionario administrativo está realizando una función más propiamente de empresa que de autoridad.

$\mathrm{Y}$ partiendo de que, como veremos muy pronto, toda la actividad de orden provincial se desarrolla en servicios concretos de Beneficencia, de Obras públicas, de Asistencia social, en servicios de auxilio o 61 
de protección al desarrollo de la agricultura y de la ganadería, yo me pregunto: ¿Por qué cuando se habla de la Corporación municipal se piensa en el Gerente, y en Norteamérica, donde se han buscado nuevos métodos de organización para la Administración municipal, el sistema del Mayor se sustituye por el sistema de gobierno por Comisión o de gobierno por Gerencia, esto es, de administración por un número reducido de Gestores y de administración centralizada desde el punto de vista de la acción, desde el punto de vista de la ejecución, en una persona con cargo de naturaleza idéntica a la del Gestor de cualquier empresa privada de carácter mercantil o de carácter industrial si hay defensores del sistema de Gerente en la Administración municipal, es que resultaría extraño pensar en la existencia del Gerente en la Administración provincial?

En la Administración municipal puede haber un Ayuntamiento, una Comisión permanente, un presidente de ellos; puede haber un Alcalde, como nosotros le llamamos. Este será presidente de la Corporación, podrá ser la persona en quien esté personificada la representación municipal; pero para los efectos de administrar ejecutivamente, para los efectos de regir la Administración ciertamente que como Jefe de la Administración municipal, hay funciones distintas de las que desarrolla el Secretario, como son funciones distintas en un Banco las que tiene el Consejo de la entidad, cada uno de los Consejeros, las que corresponde al Presidente del Consejo de Administración, las que tiene la persona que se llama Director, Consejero-Delegado y Gerente, de las del que se llama Secretario del Establecimiento bancario, Secretario de la entidad.

Si en las empresas está perfectamente clara y generalmente admitida la diferenciación entre Consejo de Administración, Presidente del mismo, representante jurídico de la entidad, Consejero-Delegado o Gerente y Secretario, i es que en la Administración provincial no cabría admitir la existencia del Gerente? Quede el interrogante, cuya respuesta depende, naturalmente, del carácter atribuído a las funciones de la Administración provincial, que cuanto más analogía tengan con actividades de empresa más requerirán utilizar los métodos de éstas en lugar de los burocráticos públicos.

No hay tiempo para ir examinando tantas y tantas cuestiones como surgen al tratar de los problemas que existen en los diversos aspectos de la administración de servicios de índole puramente municipal. Pero quiero dejar sentada la posibilidad de la existencia de Gerente de los servicios provinciales para ir trazando e! camino de 62 una administración de índole provincial en la que aislemos todo lo 
posible el aspecto político, que tanto dominó antes en la vida de las Diputaciones provinciales, para ceñir la actuación de los órganos que existan en el porvenir exclusivamente a la parte administrativa, a la realización de los servicios, a la satisfacción de las necesidades de protección, de fomento de los intereses públicos circunscritos dentro de la demarcación territorial provincial.

José GASCON MARIN 